\title{
Erratum: An analysis of the effects of equalisation funds on service delivery in selected local authorities in Zambia
}

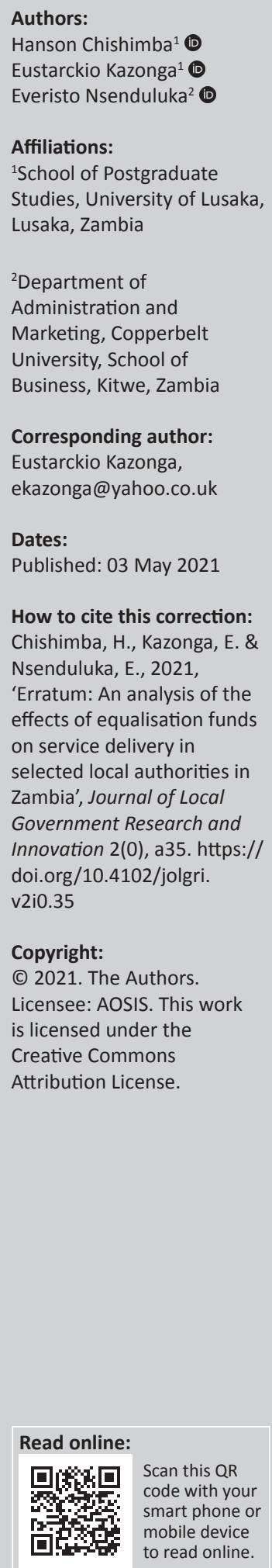

\section{Copyright:}

(C) 2021. The Authors.

Licensee: AOSIS. This work

is licensed under the

Creative Commons

Attribution License.

In the version of this article initially published, Chishimba, H., Kazonga, E. \& Nsenduluka, E., 2020, 'An analysis of the effects of equalisation funds on service delivery in selected local authorities in Zambia', Journal of Local Government Research and Innovation 1(0), a14. https:/ / doi. org/10.4102/jolgri.v1i0.14, the article section was given incorrectly. The correct section should be Original Research instead of Review Article.

This correction does not alter the study's findings of significance or the overall interpretation of the study's results. The publisher apologises for any inconvenience caused. 